\title{
Functionality of Elderly Persons: A Comparison Between Institutionalized and Non - Institutionalized Elderly Persons in Nairobi City County, in Kenya
}

\author{
Judy Wairimu Mugo ${ }^{1}$, Vincent Onywera ${ }^{2}$, Judith Waudo ${ }^{3}$, Ochieng George Otieno ${ }^{4}$ \\ ${ }^{1}$ Department of Population and Reproductive Health, School of Public Health, Kenyatta University, Nairobi, Kenya \\ ${ }^{2}$ Department of Recreation Management and Exercise Science, School of Pure and Applied Sciences, Kenyatta University, Nairobi, Kenya \\ ${ }^{3}$ Department of Food, Nutrition and Dietetics, School of Pure and Applied Sciences, Kenyatta University, Nairobi, Kenya \\ ${ }^{4}$ Department of Health Management and Informatics, School of Public Health, Kenyatta University, Nairobi, Kenya
}

\section{Email address:}

mugo.judy@ku.ac.ke (J. W. Mugo),wajudie@yahoo.com (J. W. Mugo), onywera.vincent@ku.ac.ke (V. Onywera), vonywera@gmail.com (V. Onywera),waudo.judith@ku.ac.ke (J. Waudo), waudojudith@yahoo.com (J. Waudo), Otieno.george@ku.ac.ke (O. G. Otieno), otienogo@gmail.com (O. G. Otieno)

\section{To cite this article:}

Judy Wairimu Mugo, Vincent Onywera, Judith Waudo, Ochieng George Otieno. Functionality of Elderly Persons: A Comparison Between Institutionalized and Non - Institutionalized Elderly Persons in Nairobi City County, in Kenya. World Journal of Public Health .

Vol. 3, No. 1, 2018, pp. 9-15. doi: 10.11648/j.wjph.20180301.12

Received: December 1, 2017; Accepted: December 23, 2017; Published: March 23, 2018

\begin{abstract}
This study compared the Functionality of Institutionalized elderly persons and that of the elderly persons living with their family and or community members using the Modified Barthel Index. Two hundred and seventy elderly men and women who met the inclusion criteria were sampled, 135 from 4 Institutions namely Mji wa Huruma, Nyumba ya Wazee Ruaraka, Kariobangi Cheshire home and Mother Teresa in Huruma and 135 from Gumba, Kariobangi, Huruma and Kawangware divisions. Data were coded and entered using EPI Info version 9 and were analyzed using SPSS version 17. There were more totally dependent elderly at Institutions (13.6\%), compared to 3\% who were Non-institutionalized. The majority of those who were able to independently go in and out of their house and in and out of bed or wheel chair were living in the Institutions of the elderly. There were no gender differences in performing ADLs. More men than women were found to have pressure sores and bed sores. The study will reference for similar studies in Kenya and other parts of the world and prompt tertiary institutions of learning to design new training programs and review existing programs to address the Functionality needs of the growing population of Elderly persons.
\end{abstract}

Keywords: Elderly, Functionality, Institutions of the Elderly Persons

\section{Introduction}

The population of older persons is increasing at a very rapid rate, all over in the world. It is projected to reach 1.2 and 2.0 billion in 2025 and 2050 respectively. In Africa, the population of older persons, 60 years and above is currently estimated to be 42 million and is projected to reach between 205 to 212 million by the year 2050. One of the biggest increases in population ageing in Africa is expected to occur in Kenya where it is projected that by 2050 , there will be a $470 \%$ increase in the number of older persons who will represent approximately $10 \%$ of the Kenyan population [1].
As people get older, degenerative conditions and diseases like diabetes, high blood pressure, cancers, joint and back pains tend to set in [2]. These conditions often lead to impaired mobility, degeneration and deterioration of the human systems especially the Musco-skeletal system [3]. According to Leveille et al., 1999, a high number of older people in most parts of the world live sedentary lives. Sedentary living leads to loss of muscle function and physical impairment [4].

In Sub Saharan Africa, the elderly persons are mainly supported by their households, family members as well as 
the clan. The traditional normative patterns where the elderly persons of the family were regarded as treasures of knowledge, respected and cared for are changing due to rapid urbanization as the youth seek employment in the urban areas leaving the elderly persons to fend for themselves. This has resulted to changes in the social structure of the community and created a more individualistic society. Joint families are giving way to nuclear families where the problem of housing and caring for the elderly persons is worsening and a new form of living and care (institutionalization) is taking shape [5].

The "activities of daily living" or ADLs are the basic tasks of everyday life. They include personal hygiene, bathing self, feeding, toileting, stair climbing, dressing, bowel control, bladder control, ambulation and chair-bed transfers (i.e., getting in and out of a bed or chair). Although persons of all ages may have problems performing the ADLs, disability prevalence rates are much higher for the elderly than for the non elderly. Within the elderly persons population, disability rates rise steeply with advancing age and are especially high for persons aged 85 and over [6]. Measurement of the activities of daily living is critical because they have been found to be significant predictors of admission to institutions of the elderly, use of home care, use of hospital services, change in living arrangements and overall Medicare expenditures. For research on the elderly, the ability to perform the ADLs has become a standard variable to include in analyses, like age, sex, marital status and income [7].

Kenya is a signatory to a range of International human rights Declarations and treaties which advocate for the rights to social security in old age such as the Livingstone Declaration of 2006 by the African Union on aging and the UN proclamation on Aging, 1992. The Kenyan Constitution 2010 under the bill of rights and fundamental freedoms, Articles 21, 43 and 57 provides for social protection for elderly members of the society as a vulnerable lot [8]. Article 21 states that the State shall enact and implement legislation to fulfill its International obligations in respect of human rights and fundamental freedoms. Article 43 guarantees all Kenyans their economic, Social and Cultural Rights (ESC), while the state will provide appropriate social security to persons unable to support themselves and their dependents. Article 57 ensures that older persons participate in the Society and personal development while living in dignity with support of state and Family [8].

The findings of this study will inform the government of Kenya in its plan to train personnel able to work on improving the functionality of the elderly, and prompt tertiary Institutions of learning to design new training programs and review existing programs to address the needs in the community on the relevance and importance of regular physical activities and exercise, equip trainees with skills on designing exercise and physical activity regimens that respond to different physical activity needs. It will also reference for further studies on the functionality of the elderly in Kenya and other parts of the world.

\section{Materials and Methods}

\subsection{The Study Design}

The study design was comparative and cross sectional. It was used to determine the Institutionalized and Noninstitutionalized elderly persons in Nairobi County in Kenya. A survey was used because it explores relationships between different variables in their natural setting and it also allows for extensive data collection within a short period of time. The design also allows for collection of both quantitative and qualitative data at the same time.

\subsection{Study Population}

The study targeted the elderly persons, both men and women aged 60 years and above. The age of the respondents was determined by their care-givers or by use of identity cards. This was also deduced from dates of important historical and social events as applied by the Registrar of births and deaths in Kenya. This question was also used to determine the soundness of mind of the elderly.

\subsection{Inclusion and Exclusion Criteria}

The study targeted elderly men and women aged 60 and above years living in the 4 institutions of the elderly in Nairobi County, who had lived in the Institution or with their family members for the last one year. It excluded subjects with cancer, end-age renal disease/terminal illnesses, cognitive impairment and those attending day care centers of the elderly.

\subsection{Sampling Technique}

A census of four institutions that consented to the study out of five was carried out. The Social welfare officer in each sampled institution was purposefully and conveniently sampled. A list of the elderly persons living in the Institutions was obtained from the Institution management and with information from the officer, those elderly who did not meet the inclusion criteria were eliminated from the list. The remaining elderly were systematically sampled and every $4^{\text {th }}$ case in the sampling frame selected for inclusion in the sample. The elderly were sampled proportionately to the number of elderly living in the institutions (Table 1), since some institutions had more elderly than others.

A list of elderly persons living in Kariobangi North, Huruma, Gumba and Kawangware divisions was obtained from the respective chiefs by the assistance of Social workers and Community health workers. A brief interview was done with either the care-giver of the elderly or the elderly person, to determine if they met the inclusion criteria. A total of 34 people were sampled from each of the four clusters. In cases where there were two elderly in a household, the older one was sampled on the assumption that they had a longer experience. 
Table 1. Names of Institutions of the Elderly in Nairobi County.

\begin{tabular}{llll}
\hline \multicolumn{2}{l}{ Name of Institution } & Population Size & Sample Size \\
\hline 1. & Mji wa Huruma, Runda & 240 & 57 \\
2. & Nyumba ya wazee Ruaraka & 38 & 11 \\
3. & Kariobangi Cheshire home & 177 & 42 \\
4. & Mother Teresa, Huruma & 105 & 25 \\
5. & Total & 560 & 135 \\
\hline
\end{tabular}

\subsection{Logistical and Ethical Considerations}

Prior to the study, approval was sought from Kenyatta University Ethical Clearance Committee (KU/R/COMM/51/167) and research Authorization sought from the National Council for Science, Technology and Innovation (NACOSTI) (NCST/RCD/14/013/299). Informed consent was also sought from the elderly and their care givers, both at non-institutions and in institutions and confidentiality was maintained on all the information and data collected. Participants were also informed about their right to discontinue their participation from the study at any point of data collection. Health counseling was given to all the elderly participants of poor functionality with an aim of improving their levels of functionality.

\subsection{Strengths and Weaknesses of the Study}

The study focused on one County, the Nairobi City County in Kenya and relied on already existing medical histories in excluding potential elderly participants from participating in the study. It however used already tested, valid and reliable data collections tool namely the Modified Barthel Index. Pretesting of the tool was done in the Thogoto home for the
Aged in Kikuyu Sub-county, Kiambu County in Kenya.

\subsection{Data Collection Techniques}

Functionality of the elderly was assessed using a Modified Barthel Index. The index consists of 10 items that measure a person's daily functioning, specifically the activities of Daily living and mobility [9]. The items included feeding, moving from wheel chair to bed and return, grooming, transferring to and from toilet, bathing, walking on level surface, going up and down stairs, dressing, continence and bowels and bladder. The items were weighted and the person received a score based on whether they have received help while doing the task. The scores for each of the items were summed to create a total score as follows; Unable -0, Attempts - 3, Moderate help -8 , Minimal help - 12, Fully independent 15. The scores for each of the items were summed to create a total score. Those who scored 0-49 were rated as being severely dependent on their caregivers. A 50-74 score was considered moderate dependency while 75-99 was rated as being minimally dependent on caregivers.

\subsection{Data Analysis}

Descriptive analyses were performed to report the distribution of the data and presented as frequencies and percentages $n(\%)$, and discrete and continuous data presented as mean. Univariate tests of differences between the levels of functionality and residence of the elderly persons were performed using Chi-squared tests and independent t-tests.

\section{Results and Discussion}

\subsection{Descriptive Characteristics of the Elderly Persons}

Table 2. Descriptive statistics by age of the Elderly Persons.

\begin{tabular}{|c|c|c|c|c|c|c|c|}
\hline \multirow[b]{2}{*}{ Age } & \multicolumn{2}{|c|}{ Residence of the Elderly Persons } & \multicolumn{2}{|l|}{ Gender } & \multicolumn{3}{|c|}{ Dependency Level } \\
\hline & Institution (\%) & Non-Institution (\%) & Male (\%) & Female (\%) & Severe (\%) & Moderate (\%) & Minimal (\%) \\
\hline $60-65$ & 10.2 & 17.1 & 13.2 & 14 & 3.4 & 7.3 & 16.6 \\
\hline $66-70$ & 12.7 & 10.7 & 11.7 & 11.7 & 1.0 & 6.3 & 16.1 \\
\hline $71-75$ & 9.8 & 5.9 & 5.9 & 9.8 & 3.4 & 2.0 & 9.8 \\
\hline $76-80$ & 10.7 & 8.3 & 9.3 & 9.8 & 2.9 & 5.9 & 10.6 \\
\hline 81 and above & 7.3 & 7.3 & 8.3 & 6.3 & 1.5 & 5.4 & 7.8 \\
\hline Total (\%) & 50 & 50 & 48.3 & 51.7 & 12.2 & 26.8 & 61.0 \\
\hline
\end{tabular}

The total number of respondents was 270 . One hundred and thirty five $(50 \%)$ of the participants were living in noninstitutions whereas $135(50 \%)$ were living in institutions of the elderly (Table 1). Majority of the participants 140 $(51.7 \%)$ were female (Table 2$)$. The youngest elderly was aged 60 years and the oldest 113 years. The mean age was $70.53 \pm 11.34$. The average height of the elderly was 157.31 $\pm 11.21 \mathrm{~cm}$ and an average weight of $52.904 \pm 8.06$. There was no significant relationship between age, gender and place of residence $\left(\chi^{2}=2.394, \mathrm{df}=4, \mathrm{p}=0.664 ; \chi^{2}=6.432, \mathrm{df}\right.$ $=4, \mathrm{p}=0.169)$ respectively. According to the National Council for Population and Development, the life expectancy of all the elderly persons has been rising for females, with a woman who reaches the age of 55 expecting to live for another 24 years. However the male pattern rose and begun to decline [10]. A similar study carried out in Venezuela found that the average age of the institutionalized group was $77.3+/-7.5$ years old and $69.5+/-7.6$ years old for the freeliving elderly group [11].

\subsection{The Dependency Level Among the Institutionalized and Non-Institutionalized Elderly Persons}

There were more totally dependent elderly persons at institutions (9.4\%), compared to Non-Institutions $(2.2 \%)$. Severe dependency (2.2\%), Moderate dependency (15.0\%) and Minimal dependency (33.3\%) of the elderly persons in 
Non-Institution was however higher than that of the elderly persons living in the Institutions. There was a significant relationship between dependency level and residence of the elderly persons $(\chi 2=14.147$, df $=4, \mathrm{p}=0.007)$ with the elderly in non-institutions (2.615 \pm 0.573$)$ being more dependent than those in institutions $(2.402 \pm 0.789)$. This could be because aging women experience lower rates of mortality and some chronic diseases compared to men. They also use health care services more often than men and consistently report more functional limitations and physical disability than their male counterparts [12]. It is hypothesized that this difference between the genders may be because there is greater prevalence and severity of arthritis and musculoskeletal disease among older women. These differences may also be because of psychosocial factors which make women more likely to report or over report on their ill health and disabilities in carrying out ADLs, while the men may underreport their infirmities. Studies that describe gender differences in levels of activity and chronic health conditions among others are however limited [13].

\subsection{Mobility of the Elderly Persons}

The largest population of elderly persons who were either chair or bed bound (19.5\%) were found to be living in the institutions of the elderly persons with only $0.8 \%$ living in Noninstitutions. About $62 \%$ of the elderly persons who could go in and out of the house were living in Non-institutions compared to $57.8 \%$ of the elderly persons who were living in institutions. There was a significant relationship between the type of residence and mobility of the elderly persons $\left(\chi^{2}=27.144, \mathrm{df}=\right.$ $2, \mathrm{p}<0.001)$. The mean mobility of the elderly persons in institutions was higher $(1.48 \pm 0.501)$ than that of the noninstitutionalized elderly $(1.38 \pm 0.488)$. Physical disability in the elderly persons begins by deficit in mobility before proceeding in the ADLs [14]. This group of elderly men and women may have been institutionalized in order to benefit from more specialized care of the professionals working in the institutions of the elderly.

There was a significant relationship between age and mobility of the elderly $(\chi 2=23.307, \mathrm{df}=3, \mathrm{p}=0.003)$ and a significant variance between age $(2.70 \pm 1.423)$ and mobility $(1.50 \pm 0.673)$ (Figure 1). There was however no significant relationship between mobility and gender $(\chi 2=4.048, \mathrm{df}=2$, $\mathrm{p}=0.132)$. This can be attributed to the fact that physical disability among the elderly persons begins by deficit in mobility before proceeding in the ADLs [14]. The elderly without disability in mobility and who are able to carry out ADLs are relatively healthy and independent.

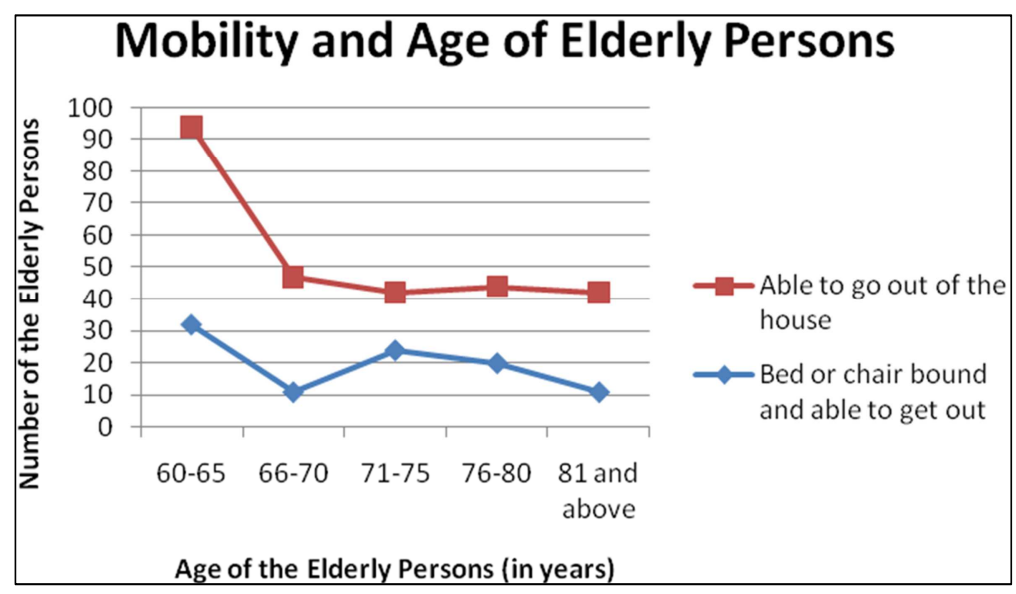

Figure 1. Mobility and age of the Elderly Persons.

\subsection{Ability of the Elderly Persons to Live Independently}

The results showed that $46.3 \%$ of all the elderly persons not able to live independently were living in the institutions of the elderly, compared to $6.3 \%$ who were living in noninstitutions. The majority of those living in non-institutions $(93.7 \%)$ were able to live independently. There was a significant relationship between the ability to live independently and the type of residence for the elderly persons $\left(\chi^{2}=92.773\right.$, df $\left.=1, \mathrm{p}=<0.001\right)$ with the mean ability of the Non-institutionalized elderly persons to live independently $(0.94 \pm 0.244)$ being higher than that of the institutionalized elderly $(0.34 \pm 4.75), \mathrm{t}=12.397, \mathrm{df}=268, \mathrm{p}$ $=<0.001$. This could be because of advancement in Public health which has made people to live longer and in the process lose their functional capacities which would make it possible for them to live independently in the Non- institutions. On the other hand, some elderly persons may not have family members to care for them and this makes them require long term care in institutions like nursing homes, community care and assisted living institutions [15]. These results contrast with those of Tolson et al., 2007, who found out that $24 \%$ of older people living in Non-institutions received support, with $32.8 \%$ of them exhibiting severe dependency in comparison with only $9.4 \%$ of the elderly requiring little involvement of the care-givers [16].

About $46.1 \%$ of the elderly Non-institutionalized men lived alone, compared to $20.7 \%$ of the women. There was a significant relationship between the gender of the elderly persons and their ability to live on their own. $(\chi 2=16.7, \mathrm{df}=$ $1, \mathrm{p}<0.001)$ and a significant variance between gender $(1.52$ $\pm 0.501)$ and ability to live independently $(0.67 \pm 0.472)$. In a similar study, Byrne et al., 2007 found out that the perception 
of safety and security, availability of transport, poor image, poor self esteem, lack of confidence, stereotypes of women's inability to make informed choices and the society's devaluing of the elderly persons results to barriers in selfhelp by the women and therefore correlated to dependence of the women [17]. In another study by Avlund et al., 2004, overall functional limitations of men and women were compared and women were more likely to report functional limitations at $52 \%$ and had a greater degree of disability mean of 0.30 against 0.18 among men $(p<0.001)$. Women also reported limitations in more of the 8 functional categories than did men $(1.8$ vs $1.1, \mathrm{p}<001)$ [18].

Table 3. Indicators of Functionality among the Elderly.

\begin{tabular}{|c|c|c|c|c|c|c|c|c|}
\hline ADLs & $\begin{array}{l}\text { Unable to } \\
\text { Perform Tasks }\end{array}$ & $\begin{array}{l}\text { Attempts Task } \\
\text { but Unsafe }\end{array}$ & $\begin{array}{l}\text { Moderate Help } \\
\text { is Required }\end{array}$ & $\begin{array}{l}\text { Minimal Help is } \\
\text { Required }\end{array}$ & $\begin{array}{l}\text { Fully } \\
\text { Independent }\end{array}$ & Chi-Square & Df & P-Value \\
\hline Personal Hygiene & $13.5 \%$ & $0.7 \%$ & $5.2 \%$ & $4.5 \%$ & $76.0 \%$ & 26.4 & 4 & $0.000 * *$ \\
\hline Bathing Self & $14.2 \%$ & $1.1 \%$ & $3.7 \%$ & $4.5 \%$ & $76.4 \%$ & 35.0 & 4 & $0.000 * *$ \\
\hline Feeding & $6.0 \%$ & $0.4 \%$ & $3.7 \%$ & $8.6 \%$ & $81.3 \%$ & 5.6 & 4 & 0.232 \\
\hline Toileting & $11.6 \%$ & $1.1 \%$ & $1.9 \%$ & $7.9 \%$ & $77.5 \%$ & 14.4 & 4 & $0.006 * *$ \\
\hline Stair Climbing & $30.3 \%$ & $12.7 \%$ & $12.0 \%$ & $8.6 \%$ & $36.3 \%$ & 52.3 & 4 & $0.000 * *$ \\
\hline Dressing & $8.6 \%$ & $1.9 \%$ & $4.5 \%$ & $4.9 \%$ & $80.1 \%$ & 20.3 & 4 & $0.000 * *$ \\
\hline Bladder Control & $9.4 \%$ & $2.6 \%$ & $4.9 \%$ & $8.2 \%$ & $74.9 \%$ & 11.7 & 4 & $0.039 * *$ \\
\hline Ambulation (Wheelchair) & $49.1 \%$ & $3.4 \%$ & $9.4 \%$ & $4.5 \%$ & $33.7 \%$ & 32.9 & 4 & $0.000 * *$ \\
\hline Chair-bed Transfers & $21.3 \%$ & $1.1 \%$ & $3.0 \%$ & $8.6 \%$ & $65.9 \%$ & 20.1 & 4 & $0.000 * *$ \\
\hline
\end{tabular}

** Significantly affects the institutionalization of the elderly.

A majority of the elderly persons $(65.9 \%)$ were found to be fully independent, whereas $21.3 \%$ were unable to perform Activities of Daily Living (ADLs) without assistance (Table 3). Physical disability in the elderly persons begins by deficit in mobility before proceeding in the ADLs [14]. The elderly persons without disability in mobility and who are able to carry out ADLs are relatively healthy and independent. Activities of Daily Living provide a basic framework to evaluate an older persons' ability to live independently. Each ADL is closely related to another and therefore when a person is not able to perform one activity, it impacts on the others [19].

Table 4. Gender Differences in performing ADLs.

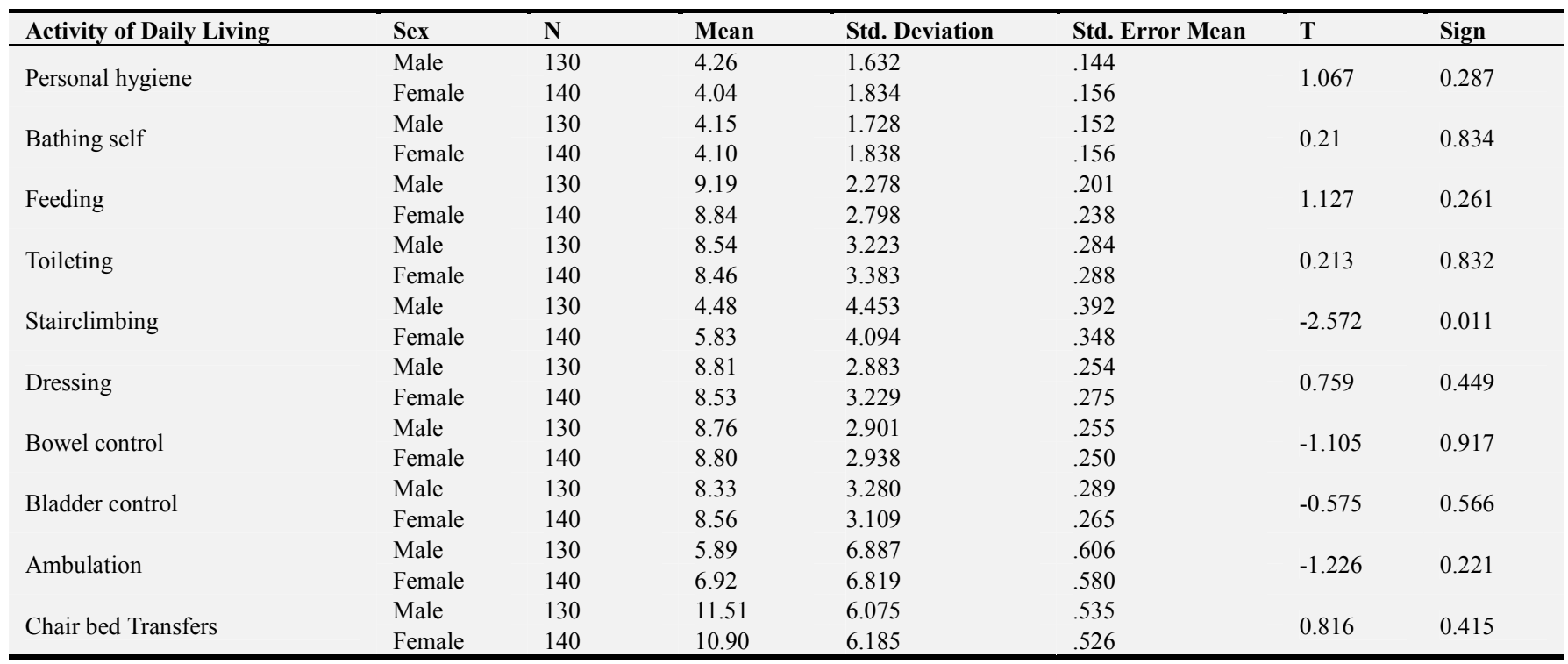

There were no differences among the two genders in toileting, bathing self, Personal Hygiene, Feeding, Dressing, Bowel Control, Bladder Control, Ambulation and Chair -bed transfers, with the exception of stair climbing where more women than men reported to have the ability to climb stairs. In a similar study conducted by Avlund et al., 2004 found that mean scores in carrying out ADLs were most significant 1.7 to 3 times greater among women $(\mathrm{p}<0.001)$. The differences in mobility functions were less but still greater among women by 1.5 times (Table 4). Women and men who reported limitations in carrying out ADLS were not statistically different in any of the 8 categories [18].

In a similar study conducted by Avlund et al., 2004 found that mean scores in carrying out ADLs were most significant 1.7 to 3 times greater among women $(p<0.001)$. The differences in mobility functions were less but still greater among women by 1.5 times. Women and men who reported limitations in carrying out ADLS were not statistically different in any of the 8 categories [18]. 


\subsection{Pressure Sores Among the Elderly}

Over $24 \%$ of the elderly male had pressure sores compared to $17.4 \%$ of the Females. There was however no significant relationship between gender and pressure sores $(\chi 2=2.212$, $\mathrm{df}=1, \mathrm{p}=0.137)$. These results contrast the findings of a similar study in Sao Paulo, where more women (95.7\%) were found to have pressure sores than men $(4.3 \%)$ on the first visit during the survey and $76.5 \%$ of the women and $23.5 \%$ of the men during the second visit were found to have pressure sores [20]. There were more elderly persons living in Institutions that had pressure Sores or Skin ulcers compared to $20.0 \%$ of those living in Non-institution. There however no significant relationship between the presence of pressure sores and place of residence $(\chi 2=0.156, \mathrm{df}=1, \mathrm{p}=$ 0.403). Aging is a risk factor for the development of pressure sores. Pressure sores among the elderly result from an interplay of both extrinsic and intrinsic risk factors, among them immobility, advanced age and incontinence [21].

\section{Conclusion}

The mean age of elderly persons in Nairobi City County in Kenya was $70.53 \pm 11.34$. The majority of the elderly who were totally dependent on their care-givers in carrying out ADLs (9.4\%) were living in the Institutions of the elderly. The majority of the elderly persons who were either chair or bed bound were living in the Institutions of the elderly, while those who were mobile and able to go in and out of their homes, chairs and beds were living in the Institutions of elderly persons.

The Non-institutionalized elderly persons were better able to live independently compared to the Institutionalized elderly, with the majority being men. Over sixty percent of all the elderly persons were able to perform activities of daily living. Pressure sores presented more among the institutionalized elderly and were most common among the men.

\section{Acknowledgements}

I would like to acknowledge the important role and assistance accorded to me by my family, research assistants, the elderly who participated in the study and their care-givers as well as the management of Mji wa Huruma home for the elderly, Kariobangi Cheshire, Nyumba ya Wazee and Mother Teresa homes of the elderly. May the Lord bless you all. Finally I would like to thank the National Council for Science, Technology, Innovation (NACOSTI) and the German Academic Exchange Service (DAAD) for sponsoring this entire work.

\section{List of Abbreviations}
ADL Activity of Daily Living
KNCHRK Kenya National Commission on Human Rights
NCPD National Council for Population and Development
SPSS Statistical Package for the Social Sciences
WHO World Health Organization

\section{References}

[1] Government of Kenya (2009a). National Housing and Population Census.

[2] Morse, C. I., Thom, J. M., Birch, K. M., \& Narici, M. V. (2005). Changes in triceps surae muscle architecture with sarcopenia. Acta physiologica Scandinavica, 183 (3), 291-298.

[3] Velikova, M. D. (2013). 20th Annual Conference of the International Society for Quality of Life Research. Qual Life Res, 22, 1-137.

[4] Leveille, S. G., Guralnik, J. M., Ferrucci, L., \& Langlois, J. A. (1999). Aging successfully until death in old age: opportunities for increasing active life expectancy. American Journal of Epidemiology, 149 (7), 654-664.

[5] Government of Kenya (2009 b). Kenya Policy Draft on Older Persons and Aging.

[6] Balzi, D., Lauretani, F., Barchielli, A., Ferrucci, L., Bandinelli, S., Buiatti, E.,... \& Guralnik, J. M. (2010). Risk factors for disability in older persons over 3-year follow-up. Age and Ageing, 39 (1), 92-98.

[7] Onder, G., Penninx, B. W., Ferrucci, L., Fried, L. P., Guralnik, J. M., \& Pahor, M. (2005). Measures of physical performance and risk for progressive and catastrophic disability: results from the Women's Health and Aging Study. The Journals of Gerontology Series A: Biological Sciences and Medical Sciences, 60 (1), 74-79.

[8] Government of Kenya. (2010). The Constitution of Kenya. Nairobi, Kenya: Government Printers.

[9] Kraft, G. H. (1999). Rehabilitation still the only way to improve function in multiple sclerosis. The Lancet, 354 (9195), 2016-2017.

[10] NCAPD, M., MOPHS, K., \& ICF, M. (2011). Kenya Service Provision Assessment Survey 2010. Nairobi: National Coordinating Agency for Population and Development, Ministry of Medical Services, Ministry of Public Health and Sanitation, Kenya National Bureau of Statistics, and ICF Macro.

[11] Kaiser, R., Winning, K., Uter, W., Volkert, D., Lesser, S., Stehle, P., \& Bauer, J. M. (2010). Functionality and mortality in obese nursing home residents: an example of 'risk factor paradox'? Journal of the American Medical Directors Association, 11 (6), 428-435.

[12] Freedman, V. A., Martin, L. G., \& Schoeni, R. F. (2002). Recent trends in disability and functioning among older adults in the United States: a systematic review. Jama, 288 (24), 3137-3146.

[13] Murtagh, K. N., \& Hubert, H. B. (2004). Gender differences in physical disability among an elderly cohort. American journal of public health, 94 (8), 1406-1411.

[14] Barberger-Gateau, P., Rainville, C., Letenneur, L., \& Dartigues, J. F. (2000). A hierarchical model of domains of disablement in the elderly: a longitudinal approach. Disability and rehabilitation, 22 (7), 308-317.

[15] Tolson, D., Rolland, Y., Andrieu, S., Aquino, J. P., Beard, J., Benetos, A., \& Franco, A. (2011). International Association of Gerontology and Geriatrics: A global agenda for clinical research and quality of care in nursing homes. Journal of the American Medical Directors Association, 12 (3), 184-189. 
[16] Byrne, G., Brady, A. M., Horan, P., Macgregor, C., \& Begley, C. (2007). Assessment of dependency levels of older people in the community and measurement of nursing workload. Journal of advanced nursing, 60 (1), 39-49.

[17] Steinberg, M. (1997). Partnership and Participation: Older Women Have Their Say About Health and Well-being. Australasian Journal on Ageing, 16 (2), 79-82.

[18] Avlund, K., Lund, R., Holstein, B. E., Due, P., Sakari-Rantala, R., \& Heikkinen, R. L. (2004). The impact of structural and functional characteristics of social relations as determinants of functional decline. The Journals of Gerontology Series B: Psychological Sciences and Social Sciences, 59 (1), S44-S51.
[19] Hyde, M., Wiggins, R. D., Higgs, P., \& Blane, D. B. (2003). A measure of quality of life in early old age: the theory, development and properties of a needs satisfaction model (CASP- Aging \& mental health, 7 (3), 186-194.

[20] Chacon, J. M. F., Blanes, L., Hochman, B., \& Ferreira, L. M. (2009). Prevalence of pressure ulcers among the elderly living in long-stay institutions in São Paulo. Sao Paulo Medical Journal, 127 (4), 211-215.

[21] Strand, T., \& Lindgren, M. (2010). Knowledge, attitudes and barriers towards prevention of pressure ulcers in intensive care units: a descriptive cross-sectional study. Intensive and critical care nursing, 26 (6), 335-342. 